\title{
FALSE LOW WATER CONTENT IN ROAD FIELD COMPACTION CONTROL USING NUCLEAR GAUGES - A CASE STUDY
}

\section{Mário Quinta-Ferreira *}

Geosciences Center, Dep. Earth Sciences, University of Coimbra Rua Sílvio Lima. 3030-790 Coimbra, Portugal. mqf@dct.uc.pt Phone: +351912563901 Fax: +351 239860501

* corresponding author

\section{José Feiteira Dias}

Inovroute - Inovação em Engenharia e Ambiente, Lda Urb. das Mélias, Lt 31, Alagoas, Santa Joana. 3810-010 Aveiro jose.feiteira@inovroute.pt

\section{Santiago Alija}

Geosciences Center, University of Coimbra Rua Sílvio Lima. 3030-790 Coimbra, Portugal santiagoalija@gmail.com

\section{Acknowledgments}

The financial support of Fundação para a Ciência e Tecnologia (FCT-MEC) through national funds and, when applicable, co-financed by FEDER in the ambit of the partnership PT2020, through the research project, UID/Multi/00073/2013 of the Geosciences Center is acknowledged. The authors thank NORace Construtores das Auto-estradas do Norte, Ace, namely Eng. Carlos Campos, for the permission to publish some of the results. The cooperation in the laboratory tests performed by Serafim Carvalho, Fernando Torres, Pedro Santos and Isabel Machado is greatly acknowledged. 


\begin{abstract}
During the construction of a highway in the north of Portugal, it was verified that in a few places the compaction control of the road fill materials presented unexpected results with the surface moisture density gauge (SMDG). The water content was lower than measured by oven drying, and the density and compaction grade were much higher than when using the sand cone. In an effort to understand the reasons for this unexpected offset, the road fill material was tested in situ with two different brands of SMDG, extra sand cone tests were performed and samples were collected at the test sites and tested in the laboratory to determine the water content by oven drying. The local geology, mineralogy, geochemistry and radiation level of the fill materials were studied. It was concluded that the incorrect results were caused by the presence of chemical elements in the road fill materials, mainly manganese, chlorine, cadmium and boron, which are able to capture the neutrons released by the SMDG, delivering a false low water content. An index to evaluate the susceptibility of the soil to present a false low water content (FLoW) is proposed. Despite the reliability of the SMDG in most fill control, it must always be used with great care, after crosschecking its results with other direct control tests.
\end{abstract}

\title{
Keywords
}

Quality Control Low water content Road fill SMDG Mineralogy

\section{Introduction}

In road fill construction, local materials are usually preferred, for economic and environmental reasons, if their characteristics are suitable for the construction operations. Adequate procedures during excavation, transportation, and placement must always be used. The selection of the best-suited layer thickness and the appropriate number of roller passages is usually based on target values defined after Proctor tests performed in the laboratory, or preferably from test fills. Compaction control during road fill construction is currently done using fast, reliable, and the simplest possible tests, performed immediately after construction, in order to facilitate and speed up the construction operations and to validate the required road fill characteristics. The water content and the dry density are the parameters most frequently measured during the quality control. They are compared with the optimum water content and the maximum dry density obtained in the Proctor test (ASTM D1557), allowing checking if the measured values are within an acceptable range. In geotechnics, techniques to determine the fill density, like the sand cone (ASTM D1556M) or rubber membrane (ASTM D2167), or to measure the water content (Lekshmi et al. 2014) using the oven drying test (ASTM D2216), the speedy test (AASHTO T 217) or burning alcohol (Bouyoucos, 1926) are often replaced by the use of nuclear devices (Goldberg et al. 1954; Christensen 1973; Bell 1987; Evett and Steiner 1995; Yuen et al. 1997). The faster quality control, the ease of operation and the good cost/benefit ratio of the surface moisture-density gauge (SMDG) (Chen et al. 2016; ASTM D6938) greatly contribute to its wide 
use in geotechnical practice. Other test methods like the Falling Weight Deflectometer (Kim et al. 2007; Kavussi et al. 2010), the Soil Stiffness Gauge (Rafiei et al. 2012; Quinta-Ferreira et al. 2012), the Plate Load Test (Kim et al. 2007) and even dynamic penetrometers (Livneh et al. 1995; Abu-Farsakh et al. 2004; Nguyen and Mohajerani 2012) can be used in the compaction control but are outside the scope of the paper. The correct performance of the SMDG relies on a suitable manufacturer calibration and on user defined moisture correction factors applied to field compaction tests (Troxler 2001, 2009). The calibration procedures have been improved since radioactive methods to measure the moisture content and density of soils started to be used (Goldberg et al. 1954; Nagy and Vértes 1968; Christensen 1973; Bell 1987; Yin and Luo 2009; Chen et al. 2016).

The unusually low water content, obtained in a few places by the SMDG, far below the values obtained by oven drying, give rise to the development of the present study, seeking to understand the reasons of this unexpected offset. Consequently, the dry density and the compaction grade computed by the SMDG were higher than expected. The observed discrepancy had a quite negative impact on the progress of the road fill construction.

\section{Site location and geology}

The anomalous results occurred in the north of Portugal at Vilarinho das Cambas, close to Vila Nova de Famalicão, between km 13.9 and km 16.3 on the A7 highway. It is located in the Hesperian Massif (Central Iberian Zone) and the bedrock of the area consists predominantly of pre-Ordovician metasediments and Hercynian granitic rocks as well as Silurian rocks belonging to the $S^{2}$ Formation (Teixeira et al. 1965), comprising schist, with interbedded carbonaceous black shale outcrop (Fig. 1). Along the river intersected at km 16.7, alluvio-colluvial sediments were accumulated. The schist is strongly mineralized, and several old mine workings were identified in the area, predominantly for tungsten (W), tin (Sn) and graphite (Gra). The schist was metasomatized in the proximity of the porphyritic coarse-grained granite. The presence of numerous fracture zones filled by quartz veins also favoured the strong mineralization (Teixeira et al. 1965).

The excavation at km 14.8 exposed brown yellowish schist with quartz veins, fractured and brecciated, that provided the road fill material named S1. From the excavation at km 15.6 black carbonaceous shale was obtained (Fig. 1 and 2), traversed by quartz veins, that was used as the road fill material named S2 (Table 1). The geotechnical characterization of samples derived from excavation, transportation and placement allowed to identify soil S1 as gravelly (GM) and S2 as argillaceous (CL), with about 50\% fines and plastic behaviour. At km 2.275, a reference sample R (Table 1) without anomalies for the in situ water content measured with the SMDG was used, consisting of silty sand (SM). 

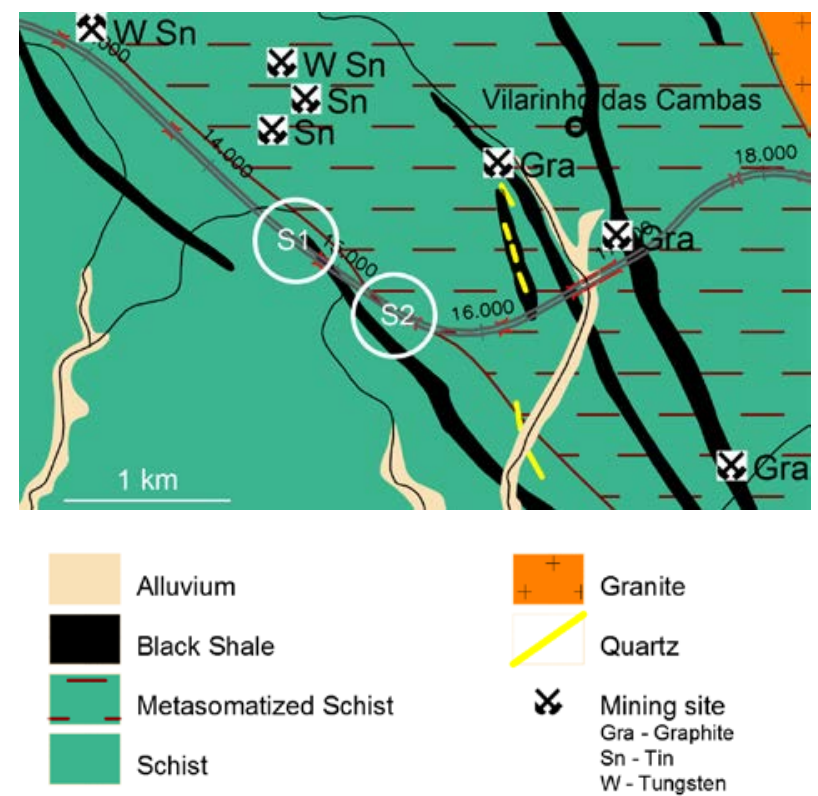

Fig. 1 Site geology (modified from Teixeira et al. 1965) indicating the locations where soils S1 and S2 were excavated

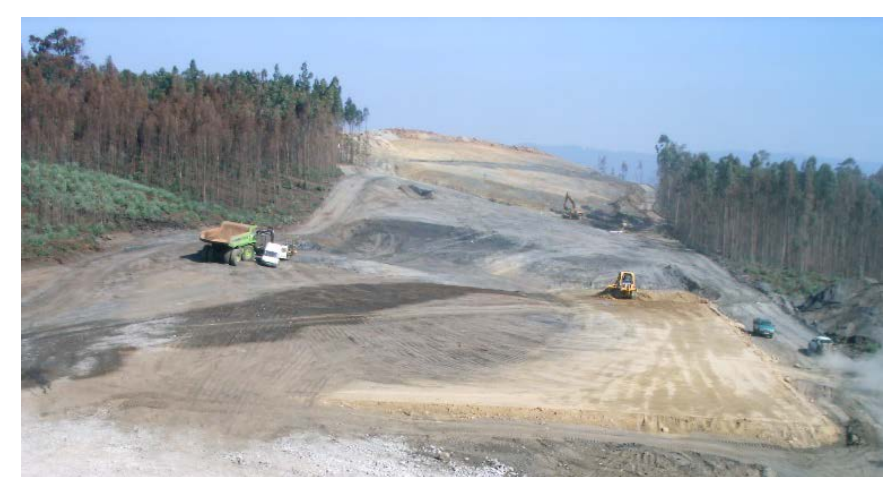

a)

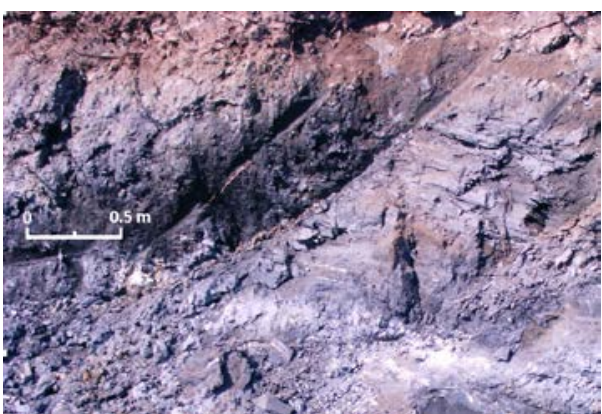

b)

Fig. 2 a) View of construction site with black shale mixed with brown schist; b) detail of the black shale.

\section{Problem characterization}

At the start of the work, a combination of direct techniques (sand cone and oven) and indirect techniques (SMDG) was used and gave good agreement. The routine calibrations and corrections were carefully performed (Troxler 2001, 2009).

Only the soils excavated between km 14.3 and 16.3 exhibited anomalous low water content when measured with the SMDG. Their geotechnical properties are presented in Table 1.

To understand the causes of the water content offset between the laboratory tests and the field values obtained by the SMDG, two different brands of SMDG were used, extra sand cone tests were carried out, the geology and mineralogy of the site was analysed and the gamma radiation level was measured using a 
scintillation counter. The chemical composition of the road fill material was obtained in situ, using a portable X-ray fluorescence (XRF) equipment (ThermoFisher 2016).

The decision to use two different brands of SMDG (Troxler 3440 and CPN) resulted from the fear of a possible malfunction of the nuclear equipment currently used during the quality control operations. In situ sand cone tests were also carried out, in order to compare the density with the SMDG values. Additionally, soil samples were collected in the test locations and their water content was measured in the laboratory by oven drying. The results are summarized in Tables 2 and 3. The fill materials S1 and S2 showed an average water content measured with the SMDG (CPN and Troxler) ranging from $4.5 \%$ to $7.9 \%$ below the water content obtained by oven drying. Accordingly, the dry density computed by the SMDG presented values above those obtained with the sand cone test, on average between 1.7 and $2.5 \mathrm{kN} / \mathrm{m}^{3}$. For the compaction grade, the values obtained with the SMDG range from 8.6 and $12.8 \%$ above those obtained with the sand cone. The implementation of the compaction control of the road fill experienced strong difficulties due to the unexpected low water content values, delivering a higher dry density and artificially increasing the compaction grade.

As the compaction grade obtained by the sand cone was lower than by the SMDG, it was considered safer to reject the results of the last device, avoiding the possibility of under compaction of the road fill. Both SMDG brands confirmed this nonconformity corresponding to a low moisture content, although the values delivered by each device at each test site did not match perfectly. Having eliminated the possibility of a gross technical failure of the SMDG, other causes were sought to understand this anomaly.

Table 1 Characteristics of the road fill soil samples. Samples S1 and S2 presented anomalous SMDG results. Sample R had no problems and was used as reference

\begin{tabular}{|c|c|c|c|c|}
\hline Soil & & S1 & $\mathrm{S} 2$ & $\mathrm{R}$ \\
\hline $\begin{array}{l}\text { Source } \\
\text { location }(\mathrm{km})\end{array}$ & & 14.800 & 15.650 & 2.275 \\
\hline Depth (m) & & $2-3$ & $2-3$ & $2-3$ \\
\hline $\begin{array}{l}\text { Source } \\
\text { Lithology }\end{array}$ & & $\begin{array}{l}\text { Brown schist } \\
\text { (with fractured } \\
\text { quartz veins) }\end{array}$ & $\begin{array}{c}\text { Black shale } \\
\text { (weathered; with } \\
\text { quartz veins) }\end{array}$ & $\begin{array}{c}\text { Decomposed granite } \\
\text { (porphyritic, medium } \\
\text { grained) }\end{array}$ \\
\hline \multirow{3}{*}{ Grain size (\%) } & $<19.0 \mathrm{~mm}$ & 89.53 & 89.05 & 93.4 \\
\hline & $<4.75 \mathrm{~mm}$ & 71.50 & 65.23 & 72.1 \\
\hline & $<0.074 \mathrm{~mm}$ & 46.89 & 50.93 & 13.9 \\
\hline Liquid & limit (\%) & -- & 35 & -- \\
\hline Plasticity & limit (\%) & -- & 19 & -- \\
\hline Plasticity & index (\%) & NP & 16 & NP \\
\hline Sand & equivalent (\%) & 11 & 15 & 24 \\
\hline \multirow[t]{2}{*}{ Proctor test } & $\gamma \mathrm{d}_{\text {máx }}\left(\mathrm{kN} / \mathrm{m}^{3}\right)$ & 19.81 & 19.50 & 19.60 \\
\hline & $\mathrm{W}_{\text {ópt }}(\%)$ & 10.37 & 13.06 & 10.50 \\
\hline \multirow[t]{2}{*}{ CBR } & $\begin{array}{l}\text { CBR at } \\
0.95 \gamma d_{\max }\end{array}$ & 28 & 10 & 62 \\
\hline & Exp. (\%) & 1 & 3 & 0 \\
\hline \multirow[t]{2}{*}{ Classification } & ASTM & GM & CL & SM \\
\hline & AASTHO & A-4 (2) & A-6 (5) & A-1-a \\
\hline
\end{tabular}


Table 2 Summary of the water content measurements by the two nuclear devices (CPN and Troxler) and by oven drying for the road fill compacted soils

\begin{tabular}{|c|c|c|c|c|c|c|c|c|c|c|c|}
\hline \multirow[t]{2}{*}{$\mathrm{km}$} & \multirow[t]{2}{*}{ Soil } & \multirow{2}{*}{$\begin{array}{l}\mathrm{N}^{0} \text { of } \\
\text { tests }\end{array}$} & \multicolumn{3}{|c|}{ CPN } & \multicolumn{3}{|c|}{ TROXLER } & \multicolumn{2}{|c|}{ Oven } & \multirow[b]{2}{*}{ CV(\%) } \\
\hline & & & Average & $\sigma$ & CV(\%) & Average & $\sigma$ & CV(\%) & Average & $\sigma$ & \\
\hline 13.900 & & 4 & 3.7 & 0.4 & 9.7 & & & & 8.1 & 0.4 & 5.0 \\
\hline 13.925 & & 4 & 3.3 & 0.2 & 6.4 & & & & 7.4 & 1.0 & 12.9 \\
\hline 13.975 & S1 & 4 & 4.0 & 0.7 & 18.0 & 2.0 & 0.4 & 19.1 & 8.6 & 0.8 & 9.3 \\
\hline 13.987 & & 4 & 5.3 & 0.5 & 8.6 & 3.2 & 0.2 & 5.5 & 10.8 & 0.6 & 5.3 \\
\hline 14.000 & & 4 & 4.3 & 0.5 & 11.5 & 2.2 & 0.4 & 18.2 & 9.7 & 0.7 & 7.6 \\
\hline 14.975 & & 4 & 7.5 & 0.6 & 8.6 & 6.0 & 0.7 & 12.4 & 14.9 & 0.4 & 3.0 \\
\hline $14.975 d$ & & 4 & 6.5 & 0.4 & 6.0 & & & & 10.4 & 0.6 & 6.3 \\
\hline $14.975 \mathrm{e}$ & & 4 & 6.5 & 0.8 & 11.7 & & & & 10.7 & 1.4 & 12.8 \\
\hline 14.987 & S2 & 4 & 11.7 & 1.0 & 8.5 & 9.6 & 0.5 & 5.7 & 16.6 & 1.0 & 5.9 \\
\hline 15.000 & & 4 & 10.0 & 1.0 & 10.1 & 8.1 & 0.9 & 11.1 & 16.0 & 0.9 & 5.9 \\
\hline 15.301 & & 4 & 8.3 & 0.7 & 8.0 & & & & 10.5 & 0.3 & 3.2 \\
\hline 15.302 & & 4 & 7.3 & 1.0 & 13.8 & & & & 10.2 & 0.1 & 1.4 \\
\hline $2.275 d$ & $\mathrm{R}$ & 4 & 10.3 & 0.8 & 7.4 & & & & 10.1 & 0.6 & 5.9 \\
\hline $2.275 \mathrm{e}$ & & 4 & 8.5 & 0.4 & 5.3 & & & & 8.6 & 0.4 & 4.7 \\
\hline
\end{tabular}

Table 3 Compaction control of soils S1 and S2 with anomalous in situ results, and of the reference soil (R)

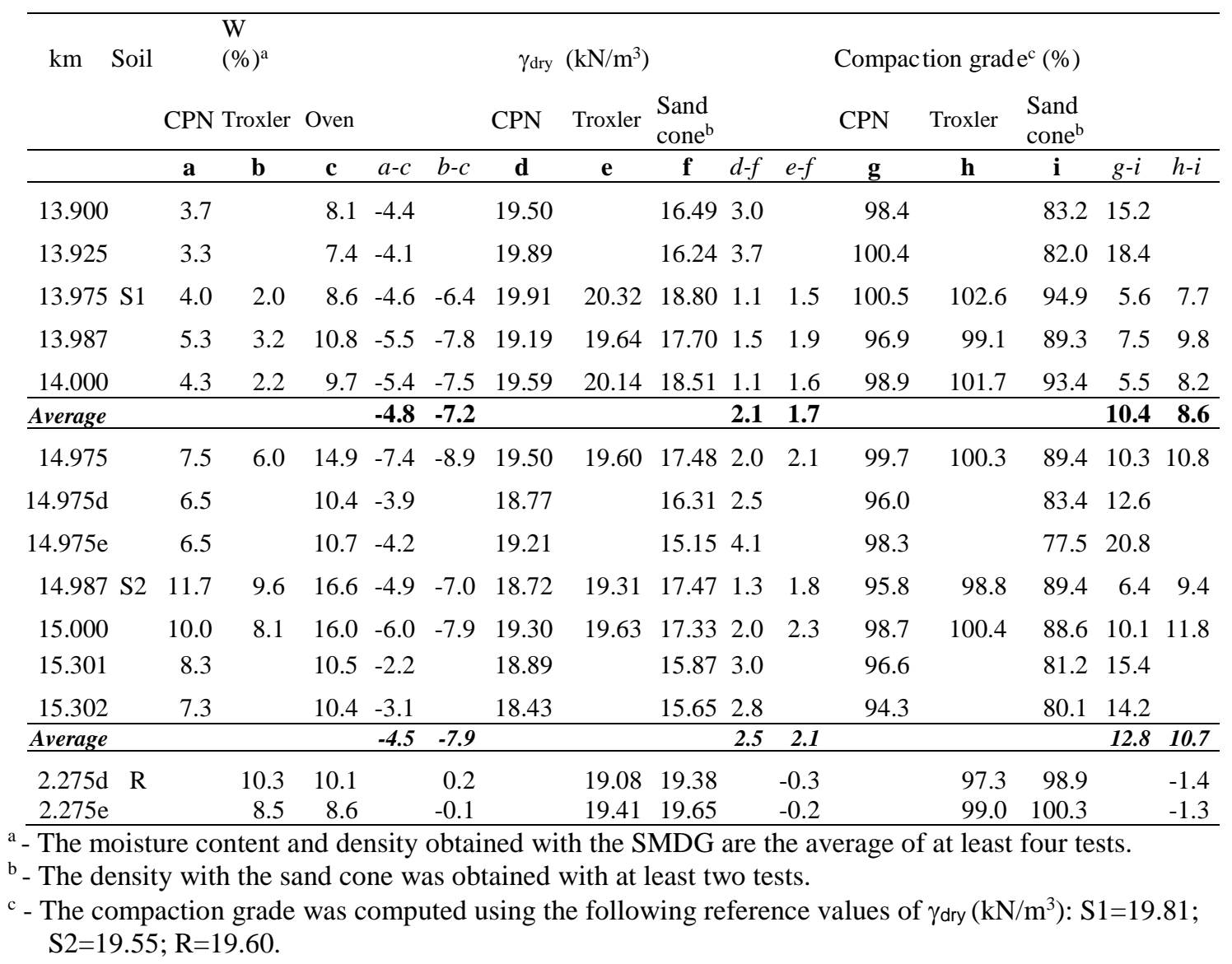




\section{The SMDG (surface moisture-density gauge)}

With the SMDG the properties of the soil are obtained indirectly by measuring the amount of radiation received at the detectors, after crossing the material being tested. The density is obtained by measuring the attenuation of the gamma radiation. The moisture content is obtained based on the detection of the neutrons emitted by the source after thermalization. The SMDG may be used in three modes: by direct transmission, backscatter, or backscatter/air-gap ratio (ASTM D6938).

In direct transmission, the technique used in this work, the rod containing the cesium-137 is lowered to the desired depth, emitting gamma radiation (photons) that are detected at the base of the SMDG, after crossing the road fill (Troxler 2009). The collision of the photons with the electrons of the soil materials reduces the amount of photons reaching the detector, so the fewer the photons that reach the detector, the higher the density of the soil (Goldberg et al. 1954, Christensen 1973, Troxler 2009). In backscatter transmission mode, the gamma photons need to be dispersed to reach the detector at the base of the gauge, since both the photon source and the detector are on the surface of the layer. Only about $10 \%$ of the photons that reach the detector arrive by direct transmission (Troxler 2009). As photons are scattered at least one time, the average energy of the photons reaching the detector is reduced, and the count statistics is lower.

The SMDG gauge also has a source of $40 \mathrm{mCi}$ of americium 241:beryllium delivering 70,000 neutrons per second (Troxler 2009). The neutrons are used to measure indirectly the hydrogen content of the material. As the neutrons collide with hydrogen atoms they undergo thermalization, whereby the fast neutrons emitted by the source are decelerated to a speed where additional collisions with hydrogen or other molecules no longer slow down the neutrons. Nineteen collisions are needed with the nucleus of the hydrogen atoms to slow a neutron, while many more collisions are necessary for other elements (Table 4). The $\mathrm{He}^{-3}$ detectors are used to count the thermalized (slow) neutrons, assuming that they are proportional to the hydrogen content of the material, as $\mathrm{He}^{-3}$ detectors are insensitive to fast (epithermal) neutrons.

\section{Discussion}

The results of the routine compaction control operations showed that along most of the road length the control operations with the SMDG did not present any problems. The anomalous low water content values were obtained in the fill materials obtained from black shale or from brown schist with quartz veins (samples S2 and S1). Other authors (Bedell et al. 2002) also have reported problems in the measurement of the water content, stating that during the construction of a tailings dam, using residual soils, the water content obtained by the SMDG was not reliable and oven-dried samples were required for all in situ tests, without being able to find a discernible pattern. While the water content determined by oven drying is a realistic value, since water is removed by evaporation, the SMDG measures indirectly the hydrogen present in the material, which is usually in the form of water. In the present work, the two SMDG devices confirmed the anomaly of the low water content. Considering as reference the water content measured by oven drying, the Troxler delivered a larger gap, almost twice that obtained by the CPN (Table 3). The calculation of the dry density using a false low moisture content delivers false high values for the compaction grade. 
Excluding the possibility of malfunction of the SMDG, a false low moisture content can be understood based on the mineralogy of the soils used in the fill (Grimaldi et al. 1994, Yuen et al. 1997). A false low water content is rare and may occur when the ground has chemical elements that capture or absorb neutrons in their nuclei, quantitatively described as the thermal absorption cross-section (TACS, Table 4). The higher the thermal absorption cross-section, the greater the ability of the chemical element to capture neutrons. Some of the most abundant natural elements like cadmium, boron, chlorine, manganese, iron, titanium or uranium are able to capture neutrons, influencing the results of the SMDG (Troxler 2009). Among stable elements, Gadolinium ( ${ }^{157} \mathrm{Ga}$ ) with 254,000 barn has the highest cross section (Rauch et al. 1999, Chadwick et al. 2011), but it is quite rare.

As illustrated in Fig. 1, soil S1 was obtained in a contact zone between metasomatized schist and the schist with fractured quartz veins, very close to an outcrop of black shale. Soil S2 was obtained from an outcrop of black shale with abundant quartz veins. Brecciated quartz veins, abundant iron oxides, and other metallic mineralization explained the ancient mining operations for wolfram (wolframite), tin (cassiterite) or graphite, now abandoned. Cadmium, which is an element with a quite high neutron absorption capacity (Table 4), was detected in sample S2 (Table 5). Sphalerite (4[ZnS]) that was present in the mineralized zones can have up to $0.5 \%$ of cadmium (Cd) (Battey and Pring 1997). Considering the 3306 ppm obtained for $\mathrm{Zn}$ in sample S2, the $104 \mathrm{ppm}$ of cadmium measured is consistent with a maximum of $0.5 \%$ of cadmium in the sphalerite. Another element that has a huge thermal absorption cross-section is boron (B), which is found in tourmalines $\left(3\left[\mathrm{AB}_{3} \mathrm{C}_{6}\left\{\mathrm{Si}_{6} \mathrm{O}_{18}\right\}\left(\mathrm{BO}_{3}\right)_{3}(\mathrm{O}, \mathrm{OH})_{3}(\mathrm{OH}, \mathrm{F})\right]\right)$ (Battey and Pring 1997). This mineral is present in quartz veins and in the schist in contact zones. Unfortunately, the portable XRF equipment was not able to detect boron (ThermoFisher 2016). Another chemical element with a neutron absorption capacity is chlorine, which was quite abundant in sample S1, and which is present in minerals such as apatite, which occur either in pegmatite or in schist. Other elements like iron, aluminium and silicon are less able to capture neutrons, and do not pose serious problems, unless they are quite abundant in the soil (Grimaldi et al 1994). Iron is more relevant for sample S2 with the higher iron content. Minerals like biotite, tourmaline and wolframite have iron in their structure. Aluminium, despite having a smaller cross-section than hydrogen was found in significant quantities in sample S1. The chemical composition of muscovite, biotite and tourmaline includes aluminium. Despite the small cross-section of silicon, it is the most abundant element in all samples (Table 4) and is mainly present in quartz, feldspars, muscovite, biotite and tourmalines.

The natural gamma radiation of the road fill materials was measured with a scintillation counter. The results showed gamma radiation slightly above the regional background, confirming the presence of small quantities of uranium, measured in sample S2 (Table 5). Uranium retains neutrons in its nuclei, despite having a small thermal absorption cross-section and a very high number of collisions to thermalization, but by fission, uranium also releases fast neutrons.

The capture of neutrons and the large number of collisions to thermalization of several chemical elements reduces the number of neutrons available to be thermalized, with the result that fewer neutrons than expected will reach the detectors, delivering the false low water content identified with the SMDG. The results confirm that the anomalies found are related to the mineralization of the fill material. When the 
difference between the water content supplied by the SMDG and by oven drying is significant, it is necessary to introduce a correction factor for the water content in order to compensate the influence of the mineralogy.

For proper use of the SMDG, it is necessary to operate the equipment suitably and to perform the required calibration procedures (Troxler 2001, 2009). According to Troxler (2009), other corrections may also be necessary: - for measurements done in trenches; - when the density of the material is outside the range 11 to $27 \mathrm{kN} / \mathrm{m}^{3}$; - when the amount of water is greater than $640 \mathrm{~kg} / \mathrm{m}^{3}$; - when there is a concentration of elements with atomic number above 20, such as in concrete, carbon or ferrous soil (Grimaldi et al 1994), or when there is a hydrogen-rich material such as gypsum, lime, mica, clay, fly ash, cement, organic matter, coal and phosphates, which tend to provide a false water level above the real one, which is the opposite of what we have found.

Table 4 Neutron thermalization and absorption data for elements with high cross-section, based on their natural abundance (Troxler 2009)

\begin{tabular}{cccc}
\hline Element & $\begin{array}{c}\text { Weight Fractions } \\
\text { of Earth's Crust }\end{array}$ & $\begin{array}{c}\text { Collisions to } \\
\text { Thermalization }\end{array}$ & $\begin{array}{c}\text { Thermal Absorption } \\
\text { Cross-Section TACS } \\
\text { (barn) }^{\mathrm{a}}\end{array}$ \\
\hline Hydrogen & 0.0014 & 19.0 & 0.33 \\
Boron & $*$ & 109.2 & 759.00 \\
Carbon & $*$ & 120.6 & 0.0034 \\
Nitrogen & $*$ & 139.5 & 1.90 \\
Oxygen & 0.466 & 158.5 & 0.002 \\
Sodium & 0.028 & 224.9 & 0.53 \\
Magnesium & 0.021 & 237.4 & 0.063 \\
Aluminum & 0.081 & 262.8 & 0.23 \\
Silicon & 0.277 & 273.3 & 0.16 \\
Phosphorus & 0.001 & 300.8 & 0.19 \\
Sulfur & $*$ & 311.1 & 0.51 \\
Chlorine & $*$ & 343.3 & 33.00 \\
Potassium & 0.026 & 378.0 & 2.10 \\
Calcium & 0.036 & 387.3 & 0.43 \\
Titanium & 0.004 & 461.6 & 6.10 \\
Manganese & 0.001 & 528.5 & 13.30 \\
Iron & 0.050 & 537.2 & 2.53 \\
Cadmium & $*$ & 1074.6 & 2390.00 \\
Lead & $*$ & 1975.5 & 0.17 \\
Uranium & $*$ & 2268.6 & 4.20 \\
\hline
\end{tabular}

a - barn (symbol b) is defined as $10^{-28} \mathrm{~m}^{2}\left(100 \mathrm{fm}^{2}\right)$

* - weigh fraction is less than $0.1 \%$ 
Table 5 Chemical composition and natural radiation of samples S1, S2 and R obtained by a portable XRF

\begin{tabular}{|c|c|c|c|c|}
\hline Chemistry / & Sample & S1 & S2 & $\mathrm{R}$ \\
\hline \multicolumn{5}{|l|}{ (\%) } \\
\hline $\mathrm{SiO}_{2}$ & & 55.76 & 26.50 & 26.04 \\
\hline $\mathrm{TiO}_{2}$ & & 0.58 & 0.36 & 0.55 \\
\hline $\mathrm{Al}_{2} \mathrm{O}_{3}$ & & 9.07 & 6.74 & 8.16 \\
\hline $\mathrm{Fe}_{2} \mathrm{O}_{3}$ & & 2.92 & 4.61 & 4.13 \\
\hline $\mathrm{FeO}$ & & 2.62 & 4.15 & 3.72 \\
\hline $\mathrm{MnO}$ & & 0.00 & 0.02 & 0.03 \\
\hline $\mathrm{MgO}$ & & 1.13 & 1.09 & 0.74 \\
\hline $\mathrm{CaO}$ & & 0.07 & 0.24 & 0.36 \\
\hline $\mathrm{K}_{2} \mathrm{O}$ & & 2.38 & 1.64 & 2.67 \\
\hline $\mathrm{P}_{2} \mathrm{O}_{5}$ & & 0.32 & 0.87 & 0.51 \\
\hline \multicolumn{5}{|l|}{ (ppm) } \\
\hline Magnesium & & 6791 & 6593 & 4461 \\
\hline Aluminum & & 48013 & 35664 & 43174 \\
\hline Silicon & & 260674 & 123880 & 121746 \\
\hline Phosphorus & & 1408 & 3781 & 2229 \\
\hline Sulfur & & 1893 & 95264 & 1580 \\
\hline Chlorine & & 8424 & 729 & 562 \\
\hline Potassium & & 19795 & 13600 & 22192 \\
\hline Calcium & & 535 & 1703 & 2596 \\
\hline Titanium & & 3467 & 2138 & 3289 \\
\hline Manganese & & 0 & 138 & 238 \\
\hline Iron & & 20398 & 32231 & 28881 \\
\hline Cadmium & & 0 & 104 & 0 \\
\hline Lead & & 84 & 10809 & 31 \\
\hline Uranium & & 0 & 63 & 0 \\
\hline Radiation & $(\mathrm{Bq})$ & 110 & 150 & 110 \\
\hline FLoW* & & 278 & 274 & 21 \\
\hline
\end{tabular}

* FLoW - False Low Water content index (see Eq. 1)

\section{The FLoW index (False Low Water content)}

In order to evaluate the propensity of the fill material to present a false low water content (FLoW), an index inspired by the abundance of high thermal absorption cross-section elements in the soil (Table 4) is proposed. In the FLoW index only the soil chemical elements with higher value of the thermal absorption cross-section are considered (Table 4). The chemical elements that satisfy this condition are manganese, chlorine, cadmium and boron. As the portable XRF equipment was not able to measure boron, this element was not included in the proposed index. The FLoW index is defined as follows:

$$
F L o W=\sum_{\mathrm{Mn}, \mathrm{Cl}, \mathrm{Cd}} \mathrm{ppm} * T A C S * 10^{-3}
$$

where:

FLoW $=$ False low water content index

$\mathrm{Mn}=$ manganese $\mathrm{Cl}=$ chlorine $; \mathrm{Cd}=$ cadmium

ppm = Chemical abundance of the element expressed in ppm

TACS $=$ Thermal Absorption Cross-Section 
The results computed indicate that the FLoW values can rate the susceptibility of the fill material to deliver false low water content, as presented in Table 6.

Table 6 Susceptibility of a fill material to present false low water content

\begin{tabular}{ll}
\hline FLoW index & Susceptibility \\
\hline$<50$ & very low \\
$51-100$ & moderate \\
$>100$ & very high \\
\hline
\end{tabular}

When the chemical composition of the fill material is known, the FLoW index can indicate if it is prone to present false low water content values when tested with the SMDG. The experience obtained is limited to the fill material of the present case study and wider use is required to evaluate if the FLoW index is suitable for other fill materials with different chemical compositions.

\section{Conclusions}

When compaction control is carried out using the SMDG, a specific chemical composition, due to the presence of chemical elements that are able to absorb neutrons in their nuclei like manganese, chlorine, cadmium or boron, provided a false low water content and both false high dry density and high compaction grade. This mineralogical association was only found in specific locations along the road due to local geological conditions that provided mineralization. As the main concern during the earth works control is with the geotechnical properties of the fill materials rather than the mineralogy, the false low water content results are difficult to anticipate, notably when most of the fill material exhibits correct values. In order to evaluate the susceptibility of the fill material to present a false low water content, the FLoW index was proposed, based on the chemical elements that are more prone to capture neutrons.

The use of the SMDG for quality control of fills is vulnerable to errors, requiring rigorous confirmation and interpretation, together with systematic calibration and correction procedures in order to guarantee the validity of the results. Direct techniques to determine density such as the sand cone or to determine the water content by oven drying must always be used during compaction control, and systematically whenever unexpected results are obtained with the SMDG.

\section{References}

AASHTO T 217 (2014) Determination of Moisture in Soil by Means of Calcium Carbide Gas Pressure Moisture Tester (Speedy) 
Abu-Farsakh MY, Alshibli K, Nazzal M, Seyman E (2004) Assessment of in-situ test technology for construction control of base courses and embankments. Technical Report no FHWA/LA.04/385. Baton Rouge, LA, USA: Louisiana Transportation Research Center. 126p

ASTM D1556M-15e1, Standard Test Method for Density and Unit Weight of Soil in Place by Sand-Cone Method, ASTM International, West Conshohocken, PA, 2015. DOI: 10.1520/D1556_D1556M15E01, www.astm.org

ASTM D1557-12e1, Standard Test Methods for Laboratory Compaction Characteristics of Soil Using Modified Effort (2,700 kN-m/m3), ASTM International, West Conshohocken, PA, 2012, www.astm.org

ASTM D2167-15, Standard Test Method for Density and Unit Weight of Soil in Place by the Rubber Balloon Method, ASTM International, West Conshohocken, PA, 2015. DOI: 10.1520/D2167-15, www.astm.org

ASTM D2216-10, Standard Test Methods for Laboratory Determination of Water (Moisture) Content of Soil and Rock by Mass, ASTM International, West Conshohocken, PA, 2010. DOI: 10.1520/D221610, www.astm.org

ASTM D6938-10, Standard Test Method for In-Place Density and Water Content of Soil and SoilAggregate by Nuclear Methods (Shallow Depth), ASTM International, West Conshohocken, PA, 2010. DOI: 10.1520/D6938-10, www.astm.org

Battey MH, Pring A (1997) Mineralogy for students. 3rd edition. Longman

Bedell PR, Firlotte FW, Atherton K (2002) A case record of tailings dam construction using residual soils. Can Geotech J 39: 409-416. DOI: 10.1139/T01-094

Bell JP (1987) Neutron probe practice. 3rd edition. Wallingford, Institute of Hydrology, 51p. (IH Report No.19) (Unpublished). NERC Open Research Archive (NORA). Available: http://nora.nerc.ac.uk

Bouyoucos, GJ. (1926) Rapid determination of the moisture content of soils. Soil Science, Baltimore, 24:651-2.

Chadwick MB et al. (2011) ENDF/B-VII.1 Nuclear data for science and technology: cross sections, covariances, fission product yields and decay data. Nuclear Data Sheets 112, 12: 2887-2996. DOI: 10.1016/j.nds.2011.11.002

Chen F, He X, Wang L, Yin H (2016) Characterization and modeling of photon absorption for improved accuracy and consistency of density measurement using nuclear gauge with hydrogen effects. Transp. Infrastruct. Geotech. DOI: 10.1007/s40515-016-0028-0

Christensen ER (1973) Use of the gamma density gauge in combination with the neutron moisture probe, Proc. Isotope And Radiation Techniques In Soil Physics And Irrigation Studies, Vienna, IAEA-SM176/1: 27-42

Evett SR, Steiner JL (1995) Precision of Neutron Scattering and Capacitance Type Soil Water ContentGauges from Field Calibration. Soil Science Society of America Journal, 59, 4: 961-968

Goldberg I, Trescony LJ, Campbell Jr JS, Whyte GJ (1954) Measurement of Moisture Content and Density of Soil Masses Using Radioactivity Methods. Clays and Clay Minerals 3: 516-548

Grimaldi C, Grimaldi M, Vauclin M (1994) The effect of the chemical composition of a ferrallitic soil on neutron probe calibration. Soil Technology 7: 233-247

Kavussi A, Rafiei K, Yasrobi S (2010) Evaluation of PFWD as potential quality control tool of pavement layers. J Civ Eng Manag 16, 1: 123-129. DOI: 10.3846/jcem.2010.11

Kim JR, Kang HB, Kim D, Park DS, Kim WJ (2007) Evaluation of in situ modulus of compacted subgrades using portable falling weight deflectometer and plate-bearing load test. J Mater Civil Eng, ASCE, June, 492-499. DOI: 10.1061/(ASCE)0899-1561(2007)19:6(492)

Lekshmi SU, Singh DN, Baghini MJ (2014) A critical review of soil moisture measurement. Measurement 54: 92-105. DOI: 10.1016/j.measurement.2014.04.007

Livneh M, Ishai I, Livneh NA (1995) Effect of Vertical Confinement on Dynamic Cone Penetrometer Strength Values in Pavement and Subgrade Evaluations. Transportation Research Record 1473, pp18, TRB, National Research Council, Washington, DC 
Nagy A Z, Vértes P (1968) Correction for dry bulk density in measurements with neutron moisture gauges. Journal of Scientific Instruments (Journal of Physics E) Series 2, Vol 1: 1097-1100

Nguyen B, Mohajerani A (2012) A new lightweight dynamic cone penetrometer for laboratory and field applications. Australian Geomechanics 47, 2: 41-50

Quinta-Ferreira M, Fung E, Andrade PS, Branco FC (2012) In-place evaluation of a limestone base course modulus, using a van-integrated falling weight deflectometer (FWD) and the GeoGauge (SSG). Road Mater Pavement 13, 4: 817-831. DOI: 10.1080/14680629.2012.735794

Rafiei K, Kavussi A, Yasrobi S (2012) Construction quality control of unbound layers based on stiffness modulus criteria. J Civ Eng Manag 18, 1: 5-13. DOI: 10.3846/13923730.2011.619328

Rauch H, Zawisky M, Stellmach Ch, Geltenbort P (1999) Giant absorption cross section of ultracold neutrons in Gadolinium. Phys. Rev. Lett. 83, 24: 4955-4958. DOI: 10.1103/PhysRevLett.83.4955

Teixeira C, Medeiros AC, Assunção CT (1965) Carta geológica de Portugal, Folha 9-A, Póvoa do Varzim (in Portuguese)

ThermoFisher (2016) Niton XL3t GOLDD+ Series Mining Analyzers. https://www.thermofisher.com/order/catalog/product/XL3TGOLDDPLUS. Accessed 30 May 2016

Troxler (2001) The importance of the application of necessary moisture correction factors to field compaction tests made with nuclear moisture gauges. Application brief, 3p, Troxler Electronic Laboratories, Inc., NC 27709, USA. http://www.troxlerlabs.com/downloads/pdfs/moist_correct.pdf. Accessed 30 May 2016

Troxler (2009) Manual of operation and instructions. Model 3440. Surface Moisture-Density Gauge. 210p, Troxler Electronic Laboratories, Inc., NC 27709, USA. http://www.troxlerlabs.com/downloads/pdfs/3440/3440manual.pdf. Accessed 30 May 2016

Yin HM, Luo Z. (2009) Investigation of the Nuclear Gauge Density Calibration Method, Road Materials and Pavement Design, 10:3, 625-645. DOI: 10.1080/14680629.2009.9690217

Yuen STS, Wang QJ, Styles JR, McMahon TA (1997) Neutron probe technique for moisture monitoring in landfills. Sardinia 97, Sixth Int. Landfill Symposium, Cagliari, Italy, 11p 